\title{
Whole genome sequencing of apparently mutation-negative MEN1 patients
}

\author{
Samuel Backman', Duska Bajic², Joakim Crona², Per Hellman'1, Britt Skogseid² and \\ Peter Stålberg ${ }^{1}$
}

Departments of ${ }^{1}$ Surgical Sciences and ${ }^{2}$ Medical Sciences, Uppsala University, Uppsala, Sweden

Correspondence should be addressed to S Backman

Email

samuel.backman@surgsci. uu.se

\begin{abstract}
Objective: Multiple endocrine neoplasia type 1 (MEN1) is an autosomal dominant syndrome usually caused by loss-offunction mutations in the MEN1 gene. However, a minority of patients who fulfill the criteria for MEN1 are not found to harbor MEN1 mutations. Besides, some of these individuals, present with a subtly different phenotype suggestive of sporadic disease. The aim of the present study was to investigate the genetic architecture of mutation-negative MEN1. Design: Fourteen patients with a clinical diagnosis $(n=13)$ or suspicion $(n=1)$ of MEN1 who had negative genetic screening of the MEN1 gene were included.

Methods: Constitutional DNA from the included patients, as well as tumor DNA from six of the patients, was subjected to whole genome sequencing. Constitutional variants were filtered against population databases and somatic variants were studied under a tumor-suppressor model.

Results: Three patients carried pathogenic variants (two splice-site variants, one missense variant) in MEN1 that had not been detected during routine clinical sequencing, one patient carried a pathogenic variant in CASR and one patient carried a gross deletion on chromosome $1 \mathrm{q}$ which included the $C D C 73$ gene. Analysis of matched tumor DNA from six patients without mutations did not detect any recurrent genes fulfilling Knudson's two-hit model.

Conclusion: These results highlight the possibility of germline mutations being missed in routine screening, the importance of considering phenocopies in atypical or mutation-negative cases. The absence of apparent diseasecausing mutations suggests that a fraction of MEN1 mutation-negative MEN1 cases may be due to the chance occurrence of several endocrine tumors in one patient.
\end{abstract}

\section{Introduction}

Multiple endocrine neoplasia type 1(MEN1) is an autosomal dominant disease characterized hyperparathyroidism, pituitary adenomas, and neuroendocrine tumors of the pancreas. Additionally, patients may develop tumors in a range of tissues, including the lungs, adrenals and the thymus (1). The penetrance is near-complete penetrance by the sixth decade of life (2). The prognosis of each individual patient depends on his or her particular manifestations of the disease, but more than $70 \%$ of deaths in MEN1 patients are directly related to the disease (3). In 1988 the MEN1 gene was mapped to a narrow region on chromosome 11q13 (4), and in 1997 the gene was cloned, enabling genetic testing of patients (5). More than 1100 mutations have been reported to date, spanning all nine coding exons of the gene as well as splice sites. Since genetic testing became available, it has been demonstrated that not all patients carry a MEN1 mutation. It is currently estimated that $5-25 \%$ of all patients fulfilling clinical criteria for the MEN1 diagnosis have negative genetic tests for the MEN1 gene (1).

In theory, several explanations for this finding may be considered. Firstly, the sensitivity of conventional genetic 
testing is likely less than $100 \%$, which may account for a small number of missed true cases. Secondly, sporadic forms of two manifestations may co-occur in a patient due to mere chance, mimicking the genetic MEN1 syndrome. Moreover, mutations in another gene may phenocopy MEN1. For instance, inactivating mutations in CDKN1B have been demonstrated to cause a MEN1 phenotype in a small number of patients (6), while syndromes such as familial isolated hyperparathyroidism (FIHP) (7), familial isolated pituitary adenoma (FIPA) (8) and hyperparathyroidism-jaw tumor syndrome (HPT-JT) (9) have partially overlapping features with MEN1. Finally, epigenetic inactivation of the MEN1 gene, or postzygotic mutations occurring in a subset of an individual's cells may cause the phenotype without being detected on routine clinical genetic testing.

Mutation-negative MEN1 has recently in a Dutch national cohort study been demonstrated to be qualitatively and quantitatively different from classical MEN1-mutation-related MEN1 (10). The age at diagnosis of the first disease manifestation is higher in mutation-negative patients. Moreover, they are less likely to develop a third manifestation of the disease and live longer than mutation carriers. These data suggest that mutation-negative MEN1 patients have another milder syndrome or that they do not have a genetic syndrome but rather the chance co-incidence of two sporadic neuroendocrine tumors or one familial tumor and another sporadically developed. This is further supported by multiple studies which have demonstrated that patients without a family history of MEN1 are less likely to carry a MEN1 mutation $(11,12)$.

Whether mutation-negative MEN1 is due to sporadic co-occurrence of several neuroendocrine tumors or due to mutations in a different gene is currently an open question. We hypothesized that whole genome sequencing of constitutional DNA from MEN1 mutationnegative MEN1 patients would enlighten us by allowing detection of other disease-causing mutations in these patients or demonstrating their absence, suggesting other mechanisms for disease development, including the possibility that these patients may have developed several sporadic tumors. Consequently, we performed a whole-genome sequencing (WGS) study of germline DNA from 14 individuals with clinically diagnosed or suspected multiple endocrine neoplasia type 1 . For a subset of patients, we also performed WGS of matched tumor DNA, hypothesizing that a novel MEN-gene would behave like a tumor suppressor and conform to Knudson's two-hit model (13).

\section{Methods}

\section{Patients}

Patients with MEN1 treated at the Endocrine Surgery and Endocrine Oncology units at Uppsala University Hospital in Uppsala, Sweden between 1984 and 2012 were reviewed. The diagnosis was performed according to standard clinical criteria (1) by experienced physicians. Briefly, MEN1 was diagnosed if a patient had two of the three main MEN1-associated lesions: hyperparathyroidism, pituitary adenoma or pancreatic neuroendocrine tumor. Hyperparathyroidism was diagnosed when hypercalcemia and inappropriately elevated PTH was present. Pituitary adenomas were diagnosed on the basis of radiological findings and hormonal screening. Pancreatic NETs were diagnosed on the basis of histopathology. All patients had undergone routine clinical genetic sequencing, Briefly, the coding exons $(2,3,4,5,6,7,8,9,10)$ of the MEN1 gene are amplified by polymerase chain reaction, followed by bidirectional Sanger sequencing as outlined in (12). Patients without a detected mutation in MEN1 were identified. The selection of patients for inclusion was performed by the senior authors and included a consideration of the available biomaterials. All patients provided written informed consent and ethical approval was obtained from the Regional Ethical Review Board (Regionala etikprönningsnämnden i Uppsala, 2014/413). Further, all patients were informed of the results of this study by their physicians and were offered clinical genetic counselling.

\section{DNA extraction}

Genomic DNA was extracted from whole blood using Qiagen DNEasy Blood\&Tissue kit in accordance with the manufacturer's instructions. For patients without a clear disease-causing mutation in the constitutional DNA, from whom fresh frozen tumor material was available, DNA was extracted from matched neoplastic tissue (parathyroid or pancreatic neuroendocrine tumors) using the same kit.

\section{Whole genome sequencing}

Extracted DNA was subjected to library preparation and whole genome sequencing on an Illumina HiSeq2500 at the SNP\&Seq-platform, Science for Life Laboratory (Uppsala node). Generated reads were mapped to the reference genome (human_g1k_b37) using BWA, followed by removal of duplicate reads and base quality score recalibration using GATK. 


\section{Data availability}

There are currently no data repository accepting whole genome sequencing data that is fully compliant with the General Data Protection Regulation (GDPR). Once such a repository is available, the sequencing data will be appropriately deposited. In anticipation of this, requests for data access can be directed to the corresponding author.

\section{Germline variant calling}

Germline variants were called using HaploTypeCaller from the GATK. Variants were annotated with predicted impact using SnpEff (14), and for gnomAD (15) filtering allele frequency (16) and SweGen (17) allele count using vcfanno.

\section{Somatic variant calling}

Somatic mutations were called using FreeBayes (18) in parallel on ten CPUs using freebayes-parallel with a region size of $1 \mathrm{Mb}$. Mutations were called if they had a minimum alternate count of 4 and a minimum alternate allele fraction of $5 \%$. Mutations were annotated as somatic using vcfsamplediff. Somatic mutations were extracted using a custom script.

Variants with an allele frequency of less than $15 \%$ or an alternate allele count of less than six were subsequently filtered out, as were variants with a mean quality of the alternate allele of less than 20 . Variants were annotated with SnpEff.

\section{Somatic copy number analysis}

A file with loci to include was generated from the 1000 Genomes phase 1 high confidence SNPs by extracting the locations of SNPs with allele frequencies of 0.3 or greater from the VCF file using a custom python script. BAF and LogR files for the samples were generated using alleleCount and convertAlleleCounts.R (from ASCAT (19, 20)). ASCAT v 2.3 was applied to the BAF/LogR files.

\section{Analysis of germline variants}

Coding variants and variants in splice sites in selected genes (MEN1, CDKN1B, CASR, CDC73, RET and AIP) were manually inspected. In order to exclude false-negative results due to insufficient coverage, the coverage of all exons in the longest transcript of each of these genes, with a padding of eight bases upstream and downstream of each exon, was extracted using the igvtools (21) count function. The mean and minimum coverage for each gene was calculated using custom scripts.

For patients without credible germline driver variants in MEN1 or known phenocopy genes, all missense (or equivalent) and truncating (or equivalent) mutations in a set of 96 genes associated with DNA repair or cancer syndromes (list extracted from a recent publication on pancreatic neuroendocrine tumors (22)) with a PHRED genotype quality of 20 and a read depth of at least 10 reads were extracted and manually curated.

For the analysis of potential novel MEN genes, all missense (or equivalent) and truncating (or equivalent) mutations with a PHRED genotype quality of 20 and a read depth of at least 10 reads were extracted. These were filtered against pre-calculated filtered allele frequencies from gnomAD. The maximum credible allele frequency was calculated as $\frac{\text { Prevalence } \times \text { maximum allelic contribution }}{\text { Penetrance }}$ (16). The parameters were generously estimated to MEN1 prevalence of $1 / 10000$, maximum allelic contribution 0.25 and penetrance 0.7 , which resulted in a cutoff of $3.6 \times 10^{-5}$.

Potential novel MEN genes were studied under a tumor suppressor model in which a missense/truncating somatic variant was required in the presence of a missense/ truncating germline variant.

\section{Results}

\section{Cohort description}

Out of 128 patients in a local MEN1 database comprising the patients with a MEN1 diagnosis between 1984 and 2012 at a tertiary referral center, 33 did not have a known mutation in MEN1. Fourteen were included in this genetic study (Fig. 1). Characteristics of the included patients, including fulfilled MEN1 critera are presented in Table 1, Supplementary Table 2 and Supplementary materials (see section on supplementary materials given at the end of this article). One patient had only one disease manifestation, while 12 of the patients had 2 main MEN1 manifestations (hyperparathyroidism, pancreatic neuroendocrine tumors and pituitary adenomas), and one patient had three major manifestations. All fourteen patients had hyperparathyroidism, seven had pituitary adenomas (the majority of which were prolactinomas), and seven had pancreatic neuroendocrine tumors. The average age at the diagnosis of the first manifestation was 47 years (range 24-69 years). Of the patients, seven were female and seven were male. 


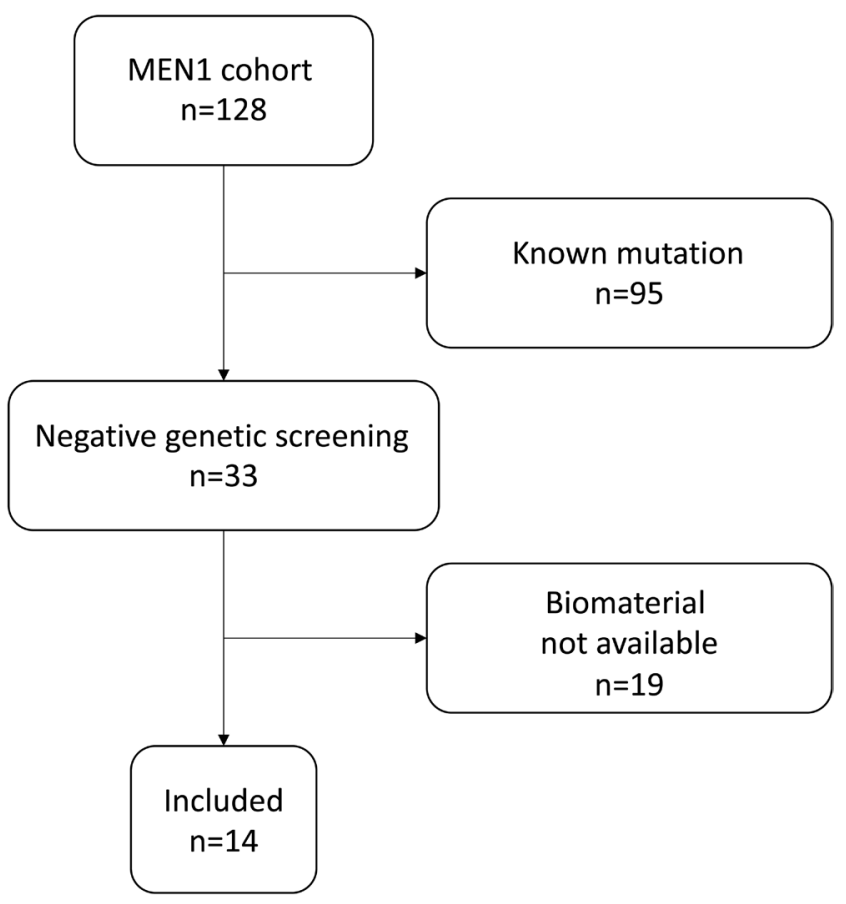

Figure 1

Flow chart of patient inclusion. The initial MEN1 cohort includes patients treated at a tertiary referral center between 1984 and 2012.

\section{Sequencing quality}

Characteristics of the germline sequencing data are presented in Supplementary Table 1. The mean coverage was $37.8 \mathrm{X}$ (range $28.9 \mathrm{X}$ to $45.2 \mathrm{X}$ ). The coverage of the MEN1, RET, CDKN1B, CASR, CDC73 and AIP coding regions and splice sites was comparable to the genomic coverage and none of the sequenced germline samples lacked coverage of any coding region in these genes. Coverage statistics for the genome and selected genes are presented in Supplementary Table 3.

\section{MEN1 mutations}

We first scrutinized variants in the MEN1 gene in order to detect any mutations that had been missed in clinical genetic screening. Three of the included patients were found to carry pathogenic (according to ACMGAMP criteria (23)) variants in the MEN1 gene (Table 2). One patient carried c.1186-2A>G, a splice-site variant disrupting the canonical GU-AG splice motif. Another patient carried the synonymous p.Arg223Arg variant, also located in a splice site. Finally, a third patient carried a p.Pro12Leu missense mutation. None of the variants were present in the gnomAD database. All variants were classified as pathogenic (Supplementary Table 2). In order to identify larger structural variants affecting the MEN1 gene, candidate germline structural variants and copy number alterations were interrogated. No variants overlapped the MEN1 locus.

\section{Known MEN1 phenocopies}

We subsequently analyzed variants in genes causing known MEN1 phenocopies. Other than a common and benign missense variant (rs2066827, gnomAD allele frequency 0.2701 ) found in two patients, no protein-altering variants were found in $C D K N 1 B$. No protein-altering variants were found in the GCM2 gene. Other than two common missense variants (rs641081 and rs4930199) found in all cases, no protein-altering variants were detected in the AIP gene. The common polymorphism rs1799939 (p.G691S, gnomAD allele frequency 0.205) in RET was detected in four patients. Additionally, one patient carried the rs201740483 (p.T1038A) variant, which is classified as Likely benign $(n=4)$ and Uncertain significance $(n=1)$ in ClinVar and has an allele frequency of 0.0006 (0.0019 in Non-Finnish Europeans) in gnomAD. All of these variants were excluded as causes of the disease on the basis of allele frequency and/or prior classifications.

One patient carried a CASR p.Ile555Val variant, previously reported in a Danish patient with familial hypocalciuric hypercalcemia (FHH). The MEN1 diagnosis in this patient was based on primary hyperparathyroidism and the presence of a neuroendocrine tumor metastasis in the liver, with an unknown primary tumor.

Patient 14 had a first-degree relative with parathyroid cancer and had been diagnosed with primary hyperparathyroidism. Copy number analysis revealed a heterozygous germline deletion of a segment on chromosome 1, spanning the CDC73 locus (Fig. 2). No other protein-altering variants were found in $C D C 73$.

\section{Variants in cancer-associated genes}

In the patients without clear pathogenic mutations, we specifically interrogated genes with known involvement in DNA damage repair or cancer syndromes, as such mutations have previously been described in patients with pancreatic neuroendocrine tumors (22). Twenty-eight variants with allele frequencies less than $1 \%$ in gnomAD were detected (Supplementary Table 4). The majority $(18 / 28)$ were classified as likely benign on the basis of ClinVar entries. The majority of the remaining variants were missense variants of unknown significance. There 
Table 1 Overview of the included patients.

\begin{tabular}{|c|c|c|c|c|c|c|c|c|c|}
\hline Case ID & $\begin{array}{l}\text { MEN1 } \\
\text { variant } \\
\text { WGS }\end{array}$ & $\begin{array}{l}\text { Other } \\
\text { variant } \\
\text { WGS }\end{array}$ & Sex & $\begin{array}{l}\text { Family } \\
\text { history }\end{array}$ & HPT & $\begin{array}{l}\text { Pituitary } \\
\text { tumor }\end{array}$ & $\begin{array}{l}\text { PNET } \\
\text { type }\end{array}$ & Adrenal & $\begin{array}{l}\text { Tumor } \\
\text { sequenced }\end{array}$ \\
\hline 1 & & & $\mathrm{M}$ & No & Yes & $\begin{array}{l}\mathrm{GH}- \\
\text { producing }\end{array}$ & & & HPT \\
\hline 2 & & & $\mathrm{~F}$ & No & Yes & Prolactinoma & & $\begin{array}{l}\text { Bilaterally } \\
\text { enlarged }\end{array}$ & HPT \\
\hline 3 & & & $M$ & No & Yes & & Insulinoma & & Insulinoma \\
\hline 4 & & & $\mathrm{M}$ & No & Yes & Prolactinoma & & $\begin{array}{l}\text { Right } \\
\text { adrenal } \\
\text { enlarged }\end{array}$ & HPT \\
\hline 5 & & & $F$ & No & Yes & & $\begin{array}{l}\text { Non- } \\
\text { functioning }\end{array}$ & & \\
\hline 6 & & $\begin{array}{l}\text { CASR } \\
\text { p.lle555Val }\end{array}$ & $\mathrm{F}$ & Yes & Yes & & $\begin{array}{l}\text { Non- } \\
\text { functioning* }\end{array}$ & & \\
\hline 7 & c. $1186-2 A>G$ & & $M$ & No & Yes & & Gastrinoma & $\begin{array}{l}\text { Bilateral } \\
\text { hyperplasia }\end{array}$ & \\
\hline 8 & p.Arg223Arg & & $\mathrm{F}$ & No & Yes & $\begin{array}{l}\text { Non- } \\
\text { functioning }\end{array}$ & $\begin{array}{l}\text { Non- } \\
\text { functioning }\end{array}$ & & \\
\hline 9 & & $\begin{array}{l}\text { ATM } \\
\text { p.Val2886fs }\end{array}$ & $\mathrm{F}$ & Uncertain & Yes & Prolactinoma & & & \\
\hline 10 & & & $M$ & No & Yes & Prolactinoma & & $\begin{array}{l}\text { Left adrenal } \\
\text { adenoma }\end{array}$ & HPT \\
\hline 11 & & & $\mathrm{~F}$ & No & Yes & & Insulinoma & & Insulinoma \\
\hline 12 & & & $\mathrm{~F}$ & Yes & Yes & $\begin{array}{l}\text { Prolactinoma } \\
\text { with } \mathrm{GH} \\
\text { secretion }\end{array}$ & & & \\
\hline 13 & p.Pro12Leu & & M & $\mathrm{N} / \mathrm{A}$ & Yes & & $\begin{array}{l}\text { Insulinoma, } \\
\text { gastrinoma }\end{array}$ & Adenoma & \\
\hline 14 & & $\begin{array}{l}C D C 73 \\
\text { deletion }\end{array}$ & $M$ & Yes** & Yes & & & & \\
\hline
\end{tabular}

More detailed clinical information is included in Supplementary Table 1.

*The patient had a liver metastasis with unknown primary, reportedly positive for Chromogranin A and pancreatic polypeptide. **Sibling afflicted with parathyroid carcinoma.

were no nonsense variants, and only a single frameshift variant: Patient 9 was found to harbor a p.Val2886fs variant in ATM which is reported as 'likely pathogenic' in ClinVar. However, the patient was heterozygous for this variant which is associated with the autosomal recessive ataxia telangiectasia syndrome, and its involvement in the tumors of this patient remains uncertain.

\section{Somatic mutations}

Tumor DNA from patients with no apparently diseasecausing germline mutation, from whom adequate tumor tissue was available, was subsequently subjected to whole genome sequencing (Table 3). After filtration for quality, read depth and effect, the tumors had on average 25.8 (range 16-34) putative protein-altering or splice-affecting mutations. Variants in Cancer Gene Census genes are presented in Table 4 and the full list of mutations are presented in Supplementary Table 5.

\section{Analysis of potential novel MEN genes}

In order to identify potential novel MEN genes, germline variants with sufficient quality that had a filtering allele frequency of $3.6 \times 10^{-5}$ or less were investigated. On average 110 (range 94-129) such variants were present in

Table 2 MEN1 variants.

\begin{tabular}{|c|c|c|}
\hline Case ID & Location & Ref \\
\hline 7 & chr11:64572290 & $\mathrm{T}$ \\
\hline 8 & chr11:64575363 & C \\
\hline 13 & chr11:64577547 & $\mathrm{G}$ \\
\hline
\end{tabular}

\begin{tabular}{c} 
Alt \\
\hline C \\
G \\
A
\end{tabular}

\begin{tabular}{l} 
ENST00000337652 \\
\hline C. $1366-2 A>G$ \\
C. $669 G>C$ \\
C. $35 C>T$
\end{tabular}

\begin{tabular}{l} 
Protein \\
\hline p.Arg223Arg \\
p.Pro12Leu
\end{tabular}

Classification*

Pathogenic

Pathogenic

Pathogenic

*Classification according to ACMG-AMP criteria (23). 


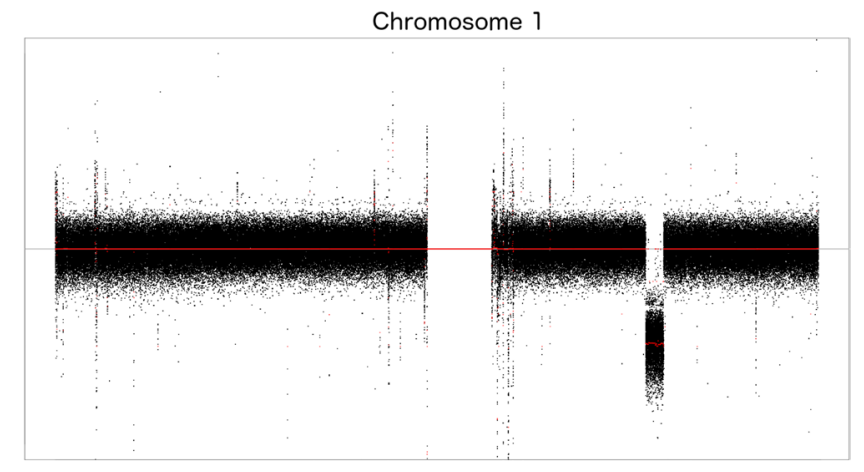

Figure 2

Gross deletion on chromosome 1 including CDC73 in patient 14.

each germline sample. No such variants occurred in the genes included in the Cancer Gene Census. Each tumornormal pair was assessed individually under a tumorsuppressor model which required independent somatic and germline hits affecting the same gene. Variants in pseudogenes and germline variants present in more than a single instance in SweGen were excluded. After filtration, only a poorly studied lincRNA (AL390778.1), found mutated in a single patient, remained. Numerous frameshift variants in this gene are present in gnomAD, rendering it a highly unlikely candidate gene.

\section{Somatic copy number variants}

Since a somatic second-hit to a tumor suppressor gene could also be caused by a copy number alteration, we analyzed the copy number profiles of the lesions. Four of the six interrogated tumors were diploid (Supplementary Figs 1, 2, 3, 4, 5 and 6). One carried a deletion of part of chromosome 1 , and amplification of part of chromosome 9 (Fig. 3). Another tumor had a low-amplitude alteration, indicative of either low tumor purity or a subclonal event.

The tumor sample with loss of part of chromosome 1 was screened for deleterious somatic mutations on the remaining copy. Two mutations remained after filtering for effect and filtering allele frequency: A missense variant in KIF1B and a missense variant in KIAA2013. Allele frequency data suggested that the tumor cells were homozygous for both variants. SIFT classified the $K I F 1 B$ variant as tolerated and the KIAA2013 variant as damaging, while PROVEAN classified the KIF1B variant as deleterious and the KIAA2013 variant as neutral. No somatic mutations were detected in this region.

In total, five out of the fourteen patients had identifiable causative constitutional genetic variants, while the remainder could not be demonstrated to carry disease-causing mutations in their germline DNA.

\section{Discussion}

We describe an in-depth genetic characterization of a series of patients with a clinical diagnosis or suspicion of MEN1, who were negative for MEN1 mutations in clinical screening. Three patients were found to carry MEN1 mutations by whole-genome sequencing. Two of these mutations affected splice sites, while one was a missense mutation. All patients with MEN1 mutations developed pancreatic neuroendocrine tumors and were the only three patients with two or more pancreatic lesions. One patient had a CDC73 deletion, and one patient had a CASR mutation. For the remaining nine patients, no causative genetic event was identified.

There are several possible reasons for these mutations being missed in clinical screening. No technique is perfectly sensitive, and variations in the protocols used occur over time. All patients had undergone Sanger sequencing of the coding exons of the MEN1 gene, which theoretically is a very sensitive method for heterozygous germline mutations. However, false-negative genetic tests are not a novel concept and may occur due to user error, technical issues, or sequence characteristics leading to for example, allelic dropout $(24,25)$. Moreover, detected mutations (i.e. mutations present in the sequencing traces) may be missed during analysis due to human error or poor sequencing data. Variant interpretation represents

Table 3 Sequenced tumor lesions.

\begin{tabular}{|c|c|c|}
\hline Case ID & Sequenced tissue & Mean coverage \\
\hline 1 & HPT & $74.2 X$ \\
\hline 2 & HPT & $74.7 X$ \\
\hline 3 & Insulinoma & $72.1 X$ \\
\hline 4 & HPT & $69.9 x$ \\
\hline 10 & HPT & $70.3 x$ \\
\hline 11 & Insulinoma & $72.4 X$ \\
\hline
\end{tabular}

\begin{tabular}{c}
\hline Number of somatic mutations \\
\hline 34 \\
29 \\
26 \\
28 \\
22 \\
16
\end{tabular}

\begin{tabular}{l} 
Somatic copy number aberrations \\
\hline No \\
No \\
No \\
No \\
Yes \\
Yes
\end{tabular}

https://eje.bioscientifica.com 
Table 4 Somatic mutations in Cancer Gene Census genes.

\begin{tabular}{l}
\hline Case ID \\
\hline 2 \\
3 \\
3 \\
4 \\
10 \\
10 \\
11 \\
\hline
\end{tabular}

\begin{tabular}{l} 
Location \\
\hline chr22:24175838 \\
chr4:87968589 \\
chr11:108119812 \\
chr5:38490309 \\
chr11:534286 \\
chr20:31022485 \\
chr10:81470419
\end{tabular}

\begin{tabular}{l} 
Ref \\
\hline$C T$ \\
$T$ \\
$T$ \\
$C$ \\
$C$ \\
AGG \\
G \\
\hline
\end{tabular}

an additional potential caveat. Indeed, two of the three additional mutations were located in or near splice-sites, and one of these also leads to a synonymous change of an amino acid-encoding codon. The interpretation of these variants may be more difficult than for example nonsense or frameshift mutations, meaning that they may be more likely to be missed. There is to the best of our knowledge no data establishing the analytical sensitivity of Sanger sequencing for MEN1 gene detection, although Sanger sequencing and targeted NGS have been shown to have identical sensitivity (26).

The present study employed whole-genome sequencing, while routine clinical genotyping typically relies on Sanger sequencing or targeted next generation sequencing. The rationale for using WGS in the present study was to enable detection of mutations in novel disease-causing genes. WGS is not a perfectly sensitive or specific method, and there is a possibility of both falsenegative findings due to for example insufficient coverage and false-positive findings due to sequencing errors, issues with alignment, and insufficiently strict criteria for variant calling. To minimize the risk for false-negative results in the present study, we calculated the coverage of each of the main genes of interest. The advantage of whole genome sequencing over exome sequencing is slightly greater power for coding variant detection and greater resolution for copy number variant detection (27), in addition to the possibility to call mutations in non-coding regions, at the cost of lower coverage and/ or higher sequencing costs. As the number of genes currently implicated in multiple endocrine neoplasia are few, with relatively specific phenotypes, there is currently no rationale to use whole genome sequencing outside of a research setting. Moreover, it has been demonstrated that intronic MEN1 mutations are a rare cause of the MEN1 syndrome, if at all (26), suggesting that sequencing of the exons and splice sites is generally sufficient. In the present study we additionally sequenced tumor DNA from a subset of the included patients in order to apply a twohit tumor suppressor model for gene discovery. While this

\begin{tabular}{lll}
\hline Alt & & Gene \\
\cline { 1 - 1 } CTTT & & SMARCB1 \\
$\mathrm{C}$ & AFF1 \\
$\mathrm{G}$ & ATM \\
$\mathrm{A}$ & LIFR \\
$\mathrm{G}$ & HRAS \\
$\mathrm{AG}$ & ASXL1 \\
$\mathrm{A}$ & NUTM2B \\
\hline
\end{tabular}

\begin{tabular}{l}
\hline Protein impact \\
\hline p.Thr366fs \\
p.Val301Ala \\
p.Asp406Glu \\
p.Gly717Val \\
p.Gly13Arg \\
p.Gly658fs \\
p.Gly545Ser
\end{tabular}

may be useful in a research setting, we do not consider it to add value in a routine clinical genetic setting.

Two patients presented with clear phenocopies. Patient 14 did not fulfill the diagnostic criteria for MEN1. However, at the time of the initial parathyroidectomy he was suspected to have MEN1 and underwent screening according to an MEN1 surveillance protocol for almost two decades. A thorough review reveals that his brother had parathyroid cancer, suggesting that the HPT-JT syndrome is a far more likely diagnosis. Indeed, this patient was found to carry a heterozygous deletion of the entire $C D C 73$ gene. Gross deletions of the CDC73 gene have recently been described in a number of patients with HPT-JT syndrome $(28,29,30)$. One patient had CASR mutation that had previously been described in a Danish cohort (31). The diagnosis of MEN1 in this patient was based on hyperparathyroidism and a liver metastasis of a neuroendocrine tumor. Based on the finding of a CASR germline mutation, it is likely that the patient had coincident familial hypocalciuric hypercalcemia or HPT and a sporadic neuroendocrine tumor. The father of this patient had received a diagnosis of HPT, and a daughter had been diagnosed with mild HPT prior to this study but has not undergone surgery. Both HPT-JT and FHH accompanied by sporadic endocrine tumors have previously been reported misdiagnosed as MEN1, and represent a diagnostic pitfall (32).

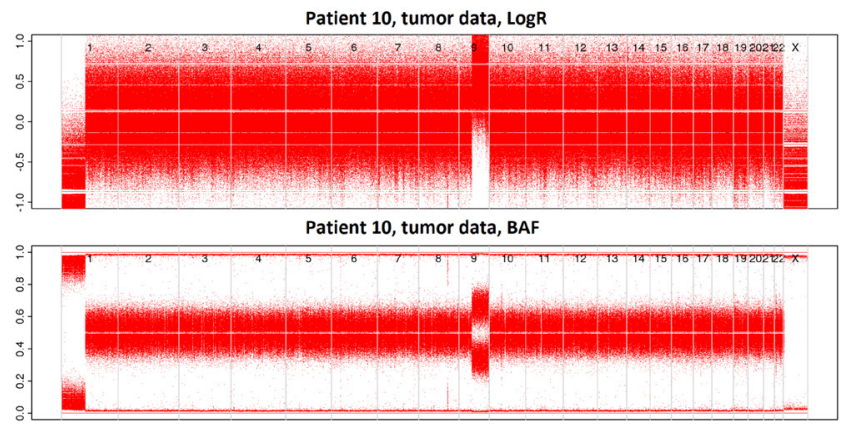

\section{Figure 3}

Somatic copy number variants. 
The absence of mutations in $C D K N 1 B$ is not surprising as these mutations have proved to be a rare cause of MEN, with approximately 20 cases described to date (33).

No recurrent somatic mutations were found in the insulinomas or parathyroid lesions, and no mutations were detected in the MEN1 or YY1 genes. Previous exome sequencing studies have demonstrated a relatively low prevalence of recurrent somatic mutations in these tumor types $(34,35)$. In the light of these studies, the present results are not surprising.

The candidate gene analyses did not identify any recurrent genes with both a somatic and a germline hit. Patient 10 carried two rare missense variants in genes located in a region of chromosome 1 that was deleted in the tumor. It cannot be excluded that one of them is related to the tumors, although in the absence of further evidence they remain variants of uncertain significance. The conflicting in silico predictions of their pathogenicity as well as the lack of recurrent hits in these genes suggest that they are not causative of the MEN1 phenotype.

A majority of the included patients (9/14) were not found to carry disease-causing or likely disease-causing germline variants. Consequently, it may be possible that mutation-negative MEN1 is due to random coincidence of two separate and genetically unrelated endocrine lesions in a single patient. Both hyperparathyroidism and pituitary adenomas are relatively common in the population, and the occurrence of one endocrine tumor in a patient might precipitate increased laboratory work-up and higher likelihood of diagnosis of a second lesion. Moreover, common genetic variants may confer a small risk increase, although this needs to be investigated in a large cohort of patients and controls. Additionally, mutations in MUTYH, CHEK2 and BRCA2 have been described in patients with pancreatic NETs (22); however, no such mutations were detected in the patients included in this study. The prevalence of primary hyperparathyroidism in certain studies approaches 1\% (36), and the prevalence of clinically apparent pituitary adenomas may be up to $0.1 \%$ (37). The prevalence of both HPT and PA increases with age and can be assumed to be even more common in older patients. Moreover, undiagnosed HPT and pituitary lesions are apparently even more common. Ten percent of healthy volunteers have detectable pituitary micro-adenomas on MRI (38) while autopsy series have demonstrated a 7 and $2.4 \%$ prevalence of parathyroid hyperplasia and adenoma (39), respectively. Given these data, we estimate that between 1\% (given the clinical prevalence) and 18\% (given the autopsy/imaging prevalence) of patients with sporadic pancreatic neuroendocrine tumors may meet the diagnostic criteria for MEN1 by chance alone. This interpretation is in line with the observation that mutation-negative patients develop MEN1-related tumors at a higher age and are less likely to develop additional manifestations of the disease (10), and the fraction of patients with a MEN1-like presentation who are not found to carry a mutation has recently been reported to possibly be higher than previously thought (40). Notably, the three patients in the present study who were found to carry MEN1 mutations all had pancreatic lesions. It is well established that patients with pancreatic involvement are more likely to carry a mutation than those with only non-pancreatic lesions. Currently, it is not clear if and how mutation-negative patients with a lack of family history should be followed.

Notably, many of the patients were diagnosed with their first endocrine tumors relatively late in life. Of the nine patients without a disease-causing mutation, four received their first diagnosis after the age of 60 years, and the mean age at diagnosis was 60 years. Moreover, the majority did not have any known family history of MEN1-associated lesions. All nine had two lesions, with HPT in combination with a pituitary adenoma being the most common combination (6/9). This is concordant with previous studies showing that the combination of HPT and pituitary adenomas without pancreatic involvement is associated with a low risk of carrying an MEN1 mutation (41).

The present study has several limitations, in addition to the small sample size. Firstly, mosaicism for MEN1 mutations has been reported (42). Somatic mosaicism for MEN1 mutations due to a postzygotic event causing mutations to be present in some tissues but not in others may contribute to genetic underdiagnosis of the syndrome. However, the absence of MEN1 mutations from tumor tissues in this cohort renders the presence of mosaicism in the present material unlikely, as a mosaic mutation leading to tumor development would be readily detected in tumor tissue due to clonal expansion. However, future studies may consider epigenetic mechanisms of MEN1 inactivation, due to for example promoter hypermethylation. This could be readily studied using bisulfite sequencing of the MEN1 promoter region. Epigenetic germline inactivation of $S D H C$ by promoter hypermethylation has been described in a patient with multiple paragangliomas (43). Such a mechanism has to the best of our knowledge not been studied in MEN1. Moreover, the analysis of potential novel MEN genes was limited to a tumor-suppressor model. While activating 
germline variants in proto-oncogenes do occur in human tumor syndromes (e.g. RET variants in MEN2 (44)), they are rare in comparison with inactivating germline variants in tumor-suppressor genes. While a tumor-suppressor gene can be identified through bi-allelic inactivation, a putative proto-oncogene would require either thorough functional characterization or a different study setup allowing segregation analysis. Nevertheless, no gene was found to have sufficiently rare missense variants in more than two samples in the current cohort, or in any of the genes included in the Cancer Gene Census. Consequently, we conclude that if such mutations cause the MEN1 phenotype, they do so in a small fraction of patients.

\section{Conclusion}

While patients with negative genetic screening for MEN1 mutations may occasionally be found to harbor a mutation upon rescreening, or to present as one of the known phenocopies, a majority (9/14) of patients in the present study were not found to carry a disease-causing germline variant. This highlights the possibility that a subset of mutation-negative MEN1 patients may fulfill the diagnostic criteria simply due to the sporadic co-incidence of two or more endocrine tumors.

\section{Supplementary materials}

This is linked to the online version of the paper at https://doi.org/10.1530/ EJE-19-0522.

\section{Declaration of interest}

J C received lecture grants from Novartis and educational grant from NETConnect (funded by Ipsen). The other authors have nothing to disclose.

\section{Funding}

This work was supported by Swedish Cancer Foundation, Uppsala University Hospital (ALF grant), Selander's foundation, Lions Foundation.

\section{Acknowledgments}

Sequencing was performed by the SNP\&SEQ Technology Platform in Uppsala. The facility is part of the National Genomics Infrastructure (NGI) Sweden and Science for Life Laboratory. The SNP\&SEQ Platform is also supported by the Swedish Research Council and the Knut and Alice Wallenberg Foundation. Birgitta Bondesson provided excellent laboratory assistance.

\section{References}

1 Thakker RV, Newey PJ, Walls GV, Bilezikian J, Dralle H, Ebeling PR, Melmed S, Sakurai A, Tonelli F, Brandi ML et al. Clinical practice guidelines for multiple endocrine neoplasia type 1 (MEN1). Journal of Clinical Endocrinology and Metabolism 201297 2990-3011. (https:// doi.org/10.1210/jc.2012-1230)

2 Machens A, Schaaf L, Karges W, Frank-Raue K, Bartsch DK, Rothmund M, Schneyer U, Goretzki P, Raue F \& Dralle H. Age-related penetrance of endocrine tumours in multiple endocrine neoplasia type 1 (MEN1): a multicentre study of 258 gene carriers. Clinical Endocrinology 200767 613-622. (https://doi.org/10.1111/j.13652265.2007.02934.x)

3 Goudet P, Murat A, Binquet C, Cardot-Bauters C, Costa A, Ruszniewski P, Niccoli P, Menegaux F, Chabrier G, Borson-Chazot F et al. Risk factors and causes of death in MEN1 disease. A GTE (Groupe d'Etude des Tumeurs Endocrines) cohort study among 758 patients. World Journal of Surgery 201034 249-255. (https://doi. org/10.1007/s00268-009-0290-1)

4 Larsson C, Skogseid B, Oberg K, Nakamura Y \& Nordenskjold M. Multiple endocrine neoplasia type 1 gene maps to chromosome 11 and is lost in insulinoma. Nature 1988332 85-87. (https://doi. org/10.1038/332085a0)

5 Chandrasekharappa SC, Guru SC, Manickam P, Olufemi SE, Collins FS, Emmert-Buck MR, Debelenko LV, Zhuang Z, Lubensky IA, Liotta LA et al. Positional cloning of the gene for multiple endocrine neoplasia-type 1. Science 1997276 404-407. (https://doi. org/10.1126/science.276.5311.404)

6 Pellegata NS, Quintanilla-Martinez L, Siggelkow H, Samson E, Bink K, Hofler H, Fend F, Graw J \& Atkinson MJ. Germ-line mutations in p27Kip1 cause a multiple endocrine neoplasia syndrome in rats and humans. PNAS 2006103 15558-15563. (https://doi.org/10.1073/ pnas.0603877103)

7 Guan B, Welch JM, Sapp JC, Ling H, Li Y, Johnston JJ, Kebebew E, Biesecker LG, Simonds WF, Marx SJ et al. GCM2-activating mutations in familial isolated hyperparathyroidism. American Journal of Human Genetics 201699 1034-1044. (https://doi.org/10.1016/j. ajhg.2016.08.018)

8 Vierimaa O, Georgitsi M, Lehtonen R, Vahteristo P, Kokko A, Raitila A, Tuppurainen K, Ebeling TM, Salmela PI, Paschke R et al. Pituitary adenoma predisposition caused by germline mutations in the AIP gene. Science 2006312 1228-1230. (https://doi.org/10.1126/ science.1126100)

9 Carpten JD, Robbins CM, Villablanca A, Forsberg L, Presciuttini S, Bailey-Wilson J, Simonds WF, Gillanders EM, Kennedy AM, Chen JD et al. HRPT2, encoding parafibromin, is mutated in hyperparathyroidism-jaw tumor syndrome. Nature Genetics 200232 676-680. (https://doi.org/10.1038/ng1048)

10 de Laat JM, van der Luijt RB, Pieterman CR, Oostveen MP, Hermus AR, Dekkers OM, de Herder WW, van der Horst-Schrivers AN, Drent ML, Bisschop PH et al. MEN1 redefined, a clinical comparison of mutationpositive and mutation-negative patients. BMC Medicine 201614182. (https://doi.org/10.1186/s12916-016-0708-1)

11 Cebrian A, Ruiz-Llorente S, Cascon A, Pollan M, Diez JJ, Pico A, Telleria D, Benitez J \& Robledo M. Mutational and gross deletion study of the MEN1 gene and correlation with clinical features in Spanish patients. Journal of Medical Genetics $2003 \mathbf{4 0}$ e72. (https://doi. org/10.1136/jmg.40.5.e72)

12 Tham E, Grandell U, Lindgren E, Toss G, Skogseid B \& Nordenskjold M. Clinical testing for mutations in the MEN1 gene in Sweden: a report on 200 unrelated cases. Journal of Clinical Endocrinology and Metabolism 200792 3389-3395. (https://doi. org/10.1210/jc.2007-0476)

13 Knudson Jr AG. Mutation and cancer: statistical study of retinoblastoma. PNAS 197168 820-823. (https://doi.org/10.1073/ pnas.68.4.820)

14 Cingolani P, Platts A, Wang le L, Coon M, Nguyen T, Wang L, Land SJ, Lu X \& Ruden DM. A program for annotating and predicting the effects of single nucleotide polymorphisms, SnpEff: SNPs in the genome of Drosophila melanogaster strain w1118; iso-2; iso-3. Fly 20126 80-92. (https://doi.org/10.4161/fly.19695) 
15 Karczewski KJ, Francioli LC, Tiao G, Cummings BB, Alföldi J, Wang Q, Collins RL \& Laricchia KM. Variation across 141,456 human exomes and genomes reveals the spectrum of loss-of-function intolerance across human protein-coding genes. biorXiv 2019. (https://doi.org/10.1101/531210)

16 Whiffin N, Minikel E, Walsh R, O'Donnell-Luria AH, Karczewski K, Ing AY, Barton PJR, Funke B, Cook SA, MacArthur D et al. Using high-resolution variant frequencies to empower clinical genome interpretation. Genetics in Medicine 201719 1151-1158. (https://doi. org/10.1038/gim.2017.26)

17 Ameur A, Dahlberg J, Olason P, Vezzi F, Karlsson R, Martin M, Viklund J, Kahari AK, Lundin P, Che H et al. SweGen: a wholegenome data resource of genetic variability in a cross-section of the Swedish population. European Journal of Human Genetics 201725 1253-1260. (https://doi.org/10.1038/ejhg.2017.130)

18 Garrison E \& Marth G. Haplotype-based variant detection from short-read sequencing. arXiv 201212073907.

19 Raine KM, Van Loo P, Wedge DC, Jones D, Menzies A, Butler AP, Teague JW, Tarpey P, Nik-Zainal S \& Campbell PJ. ascatNgs: identifying somatically acquired copy-number alterations from whole-genome sequencing data. Current Protocols in Bioinformatics 201656 15.9.1-15.9.9. (https://doi.org/ $10.1002 /$ cpbi.17)

20 Van Loo P, Nordgard SH, Lingjaerde OC, Russnes HG, Rye IH, Sun W, Weigman VJ, Marynen P, Zetterberg A, Naume B et al. Allele-specific copy number analysis of tumors. PNAS 2010107 16910-16915. (https://doi.org/10.1073/pnas.1009843107)

21 Robinson JT, Thorvaldsdottir H, Winckler W, Guttman M, Lander ES, Getz G \& Mesirov JP. Integrative genomics viewer. Nature Biotechnology 201129 24-26. (https://doi.org/10.1038/nbt.1754)

22 Scarpa A, Chang DK, Nones K, Corbo V, Patch AM, Bailey P, Lawlor RT, Johns AL, Miller DK, Mafficini A et al. Whole-genome landscape of pancreatic neuroendocrine tumours. Nature $2017 \mathbf{5 4 3}$ 65-71. (https://doi.org/10.1038/nature21063)

23 Richards S, Aziz N, Bale S, Bick D, Das S, Gastier-Foster J, Grody WW, Hegde M, Lyon E, Spector E et al. Standards and guidelines for the interpretation of sequence variants: a joint consensus recommendation of the American College of Medical Genetics and Genomics and the Association for Molecular Pathology. Genetics in Medicine 201517 405-424. (https://doi.org/10.1038/gim.2015.30)

24 Tester DJ, Cronk LB, Carr JL, Schulz V, Salisbury BA, Judson RS \& Ackerman MJ. Allelic dropout in long QT syndrome genetic testing: a possible mechanism underlying false-negative results. Heart Rhythm 20063 815-821. (https://doi.org/10.1016/j.hrthm.2006.03.016)

25 Pompanon F, Bonin A, Bellemain E \& Taberlet P. Genotyping errors: causes, consequences and solutions. Nature Reviews: Genetics 20056 847-859. (https://doi.org/10.1038/nrg1707)

26 Carvalho RA, Urtremari B, Jorge AAL, Santana LS, Quedas EPS, Sekiya T, Longuini VC, Montenegro FLM, Lerario AM, Toledo SPA et al. Germline mutation landscape of multiple endocrine neoplasia type 1 using full gene next-generation sequencing. European Journal of Endocrinology 2018179 391-407. (https://doi.org/10.1530/ EJE-18-0430)

27 Belkadi A, Bolze A, Itan Y, Cobat A, Vincent QB, Antipenko A, Shang L, Boisson B, Casanova JL \& Abel L. Whole-genome sequencing is more powerful than whole-exome sequencing for detecting exome variants. PNAS 2015112 5473-5478. (https://doi. org/10.1073/pnas.1418631112)

28 Cascon A, Huarte-Mendicoa CV, Javier Leandro-Garcia L, Leton R, Suela J, Santana A, Costa MB, Comino-Mendez I, Landa I, Sanchez L et al. Detection of the first gross CDC73 germline deletion in an HPT-JT syndrome family. Genes, Chromosomes and Cancer 201150 922-929. (https://doi.org/10.1002/gcc.20911)

29 Muscarella LA, Turchetti D, Fontana A, Baorda F, Palumbo O, la Torre A, de Martino D, Franco R, Losito NS, Repaci A et al. Large deletion at the CDC73 gene locus and search for predictive markers of the presence of a CDC73 genetic lesion. Oncotarget 20189 20721-20733. (https://doi.org/10.18632/oncotarget.25067)

30 Rubinstein JC, Majumdar SK, Laskin W, Lazaga F, Prasad ML, Carling T \& Khan SA. Hyperparathyroidism-jaw tumor syndrome associated with large-scale $1 \mathrm{q} 31$ deletion. Journal of the Endocrine Society 20171 926-930. (https://doi.org/10.1210/js.2016-1089)

31 Nissen PH, Christensen SE, Heickendorff L, Brixen K \& Mosekilde L. Molecular genetic analysis of the calcium sensing receptor gene in patients clinically suspected to have familial hypocalciuric hypercalcemia: phenotypic variation and mutation spectrum in a Danish population. Journal of Clinical Endocrinology and Metabolism 200792 4373-4379. (https://doi.org/10.1210/jc.2007-0322)

32 Turner JJ, Christie PT, Pearce SH, Turnpenny PD \& Thakker RV. Diagnostic challenges due to phenocopies: lessons from Multiple Endocrine Neoplasia type1 (MEN1). Human Mutation 201031 E1089-E1101. (https://doi.org/10.1002/humu.21170)

33 Alrezk R, Hannah-Shmouni F \& Stratakis CA. MEN4 and CDKN1B mutations: the latest of the MEN syndromes. Endocrine-Related Cancer 201724 T195-T208. (https://doi.org/10.1530/ERC-17-0243)

34 Wang H, Bender A, Wang P, Karakose E, Inabnet WB, Libutti SK, Arnold A, Lambertini L, Stang M, Chen $\mathrm{H}$ et al. Insights into beta cell regeneration for diabetes via integration of molecular landscapes in human insulinomas. Nature Communications 20178 767. (https://doi. org/10.1038/s41467-017-00992-9)

35 Newey PJ, Nesbit MA, Rimmer AJ, Attar M, Head RT, Christie PT, Gorvin CM, Stechman M, Gregory L, Mihai R et al. Whole-exome sequencing studies of nonhereditary (sporadic) parathyroid adenomas. Journal of Clinical Endocrinology and Metabolism 201297 E1995-E2005. (https://doi.org/10.1210/jc.2012-2303)

36 Press DM, Siperstein AE, Berber E, Shin JJ, Metzger R, Monteiro R, Mino J, Swagel W \& Mitchell JC. The prevalence of undiagnosed and unrecognized primary hyperparathyroidism: a populationbased analysis from the electronic medical record. Surgery 2013 154 1232-1237; discussion 1237-1238. (https://doi.org/10.1016/j. surg.2013.06.051)

37 Daly AF, Rixhon M, Adam C, Dempegioti A, Tichomirowa MA $\&$ Beckers A. High prevalence of pituitary adenomas: a crosssectional study in the province of Liege, Belgium. Journal of Clinical Endocrinology and Metabolism 200691 4769-4775. (https://doi. org/10.1210/jc.2006-1668)

38 Hall WA, Luciano MG, Doppman JL, Patronas NJ \& Oldfield EH. Pituitary magnetic resonance imaging in normal human volunteers: occult adenomas in the general population. Annals of Internal Medicine 1994120 817-820. (https://doi.org/10.7326/0003-4819120-10-199405150-00001)

39 Akerstrom G, Rudberg C, Grimelius L, Bergstrom R, Johansson H, Ljunghall S \& Rastad J. Histologic parathyroid abnormalities in an autopsy series. Human Pathology 198617 520-527. (https://doi. org/10.1016/s0046-8177(86)80043-0)

40 Kovesdi A, Toth M, Butz H, Szucs N, Sarman B, Pusztai P, Toke J, Reismann P, Faklya M, Toth G et al. True MEN1 or phenocopy? Evidence for geno-phenotypic correlations in MEN1 syndrome. Endocrine 201965 451-459. (https://doi.org/10.1007/s12020-01901932-x)

41 Klein RD, Salih S, Bessoni J \& Bale AE. Clinical testing for multiple endocrine neoplasia type 1 in a DNA diagnostic laboratory. Genetics in Medicine 20057 131-138. (https://doi.org/10.109701. GIM.0000153663.62300.F8)

42 Beijers HJBH, Stikkelbroeck NML, Mensenkamp AR, Pfundt R, van der Luijt RB, Timmers HJLM, Hermus ARMM \& Kempers MJE. Germline and somatic mosaicism in a family with multiple endocrine neoplasia type 1 (MEN1) syndrome. European Journal of Endocrinology 2019180 K15-K19. (https://doi.org/10.1530/ EJE-18-0778) 
43 Richter S, Klink B, Nacke B, de Cubas AA, Mangelis A, Rapizzi E, Meinhardt M, Skondra C, Mannelli M, Robledo M et al. Epigenetic mutation of the succinate dehydrogenase $\mathrm{C}$ promoter in a patient with two paragangliomas. Journal of Clinical Endocrinology and Metabolism 2016101 359-363. (https://doi.org/10.1210/jc.2015-3856)
44 Donis-Keller H, Dou S, Chi D, Carlson KM, Toshima K, Lairmore TC, Howe JR, Moley JF, Goodfellow P \& Wells Jr SA. Mutations in the RET proto-oncogene are associated with MEN 2A and FMTC. Human Molecular Genetics 19932 851-856. (https://doi.org/10.1093/ $\mathrm{hmg} / 2.7 .851)$

Received 8 July 2019

Revised version received 26 September 2019

Accepted 28 October 2019 